\title{
Interactive comment on "Projected changes to extreme freezing precipitation and design ice loads over North America based on a large ensemble of Canadian regional climate model simulations" by Dae II Jeong et al.
}

Dae II Jeong et al.

daeil.jeong@canada.ca

Received and published: 14 March 2019

Revised manuscript

Please also note the supplement to this comment:

https://www.nat-hazards-earth-syst-sci-discuss.net/nhess-2018-395/nhess-2018-395-

AC3-supplement.pdf

Printer-friendly version

Discussion paper

Interactive comment on Nat. Hazards Earth Syst. Sci. Discuss., https://doi.org/10.5194/nhess- 
2018-395, 2018.

NHESSD

Interactive

comment

Printer-friendly version

Discussion paper 